\title{
Does Stent-Assisted Coiling Still Have a Place in the Management of Intracranial Aneurysms?
}

$\mathbf{T}$ he article by Chalouhi et $\mathrm{al}^{1}$ in this issue of the American Journal of Neuroradiology is an interesting contribution to the debate about the present place of stent-assisted coiling (SAC) in the management of intracranial aneurysms.

Endovascular treatment plays an important role in the management of intracranial aneurysms but still has some limitations, including complex aneurysms (wide-neck, fusiform, large, and giant) and the risk of aneurysm recanalization. ${ }^{2-5}$ Stabilization of the coils in wide-neck aneurysms can be difficult; therefore balloon-assisted coiling (BAC) was developed to overcome this technical limitation of coiling. ${ }^{6,7}$ BAC is not associated with a higher rate of complications as compared with standard coiling, and some studies have even shown better anatomic outcome after BAC. ${ }^{8,9}$

Initially, SAC was introduced into the armamentarium for aneurysm treatment 10 years ago, for the treatment of wide-neck aneurysms. Clinical evaluation of this technique is mostly limited to single-center retrospective series with a limited number of patients. However, Shapiro et $\mathrm{al}^{10}$ provided a literature review in 2012 showing that the overall complication incidence was $19 \%$, with an overall death incidence of $2.1 \%$. Thromboembolic and hemorrhagic complications were observed in $10 \%$ and $2.2 \%$, respectively, and stent-related technical complications in $9 \%$. At the first treatment session, $45 \%$ of aneurysms were completely occluded, but this increased to $61 \%$ on the follow-up imaging. Instent stenosis was seen in $3.5 \%$ of cases and stent occlusion was observed in $0.6 \%$ of cases at angiographic follow-up. A learning curve was also clearly demonstrated. These results were disappointing because the morbidity of SAC was somewhat higher as compared with standard coiling, and complete occlusion rates were low.

Similar results were reported in large recent series. ${ }^{11,12}$ Lee et $\mathrm{al},{ }^{11}$ in a series of 289 patients, demonstrated a procedurerelated complication rate of $13.8 \%$, with permanent neurologic sequelae in $1.5 \%$ of patients. Follow-up imaging of 229 patients' aneurysms demonstrated a minor recanalization rate of $7.4 \%$ and major recanalization of $12.7 \%$. In-stent stenosis was observed in $12.7 \%$ of cases, stent migration in $4.5 \%$ of cases, and late delayed infarction in $4.2 \%$ of patients. Gao et al, ${ }^{12}$ in a large series of 232 patients with 239 wide-neck aneurysms treated with Neuroform SAC, also reported a high rate of procedural complications $(14.7 \%)$, with a high procedure-related morbidity of $4.2 \%$ and a mortality rate of $1.3 \%$. The overall recanalization was also relatively high, at $14.5 \%$.

Recent multicenter studies show contradictory results, including a retrospective study involving 9 US neurointerventional centers. ${ }^{13}$ There were 229 patients with 229 aneurysms, which included 32 ruptured aneurysms. The death rate was $3.5 \%$ of patients $(16 \%$ for all patients with SAH and $1.5 \%$ for elective patients). Nonfatal intracranial hemorrhage was seen in $1.0 \%$ of patients, and immediate or delayed thromboembolic events were seen in $4.4 \%$ of patients. ${ }^{13}$ In the ruptured aneurysm group, 3 of 5 deaths were related to the treatment. In patients with angiographic follow-up data, complete occlusion was observed in $59 \%$. Nineteen patients $(8.3 \%)$ had retreatment of their aneurysms, and in-stent stenosis was observed in $3.4 \%$.

In the French multicenter registry, treatment of 107 patients with 107 aneurysms with SAC was performed. ${ }^{14}$ The postprocedure rate for complete occlusion was $66.4 \%$. The rate of progressive occlusion at $12-18$ months was $14 \%$, and the rate of recurrence was $9.7 \%$. The rate of subsequent treatment was $4 \%$. The thromboembolic rate in the periprocedural period was $3.7 \%$, and the rate of delayed thromboembolic events was $3 \%$. Overall, the mortality rate at $12-18$ months was $1 \%$, and the permanent morbidity rate was $1 \%$.

The most important point is to have a direct comparison between patients treated with SAC and standard coiling (or BAC). Few series are available for this comparison, and most are single-center, retrospective series with a limited number of patients and significant differences regarding the aneurysms treated with both techniques. Piotin et $\mathrm{al}^{15}$ reported a large, retrospective, single-center series of 1137 patients with 1325 aneurysms treated without (1109 aneurysms) and with stents (216 aneurysms). Aneurysms were different in the nonstented and stented groups, according to anatomic characteristics (bifurcation/sidewall, aneurysm size, neck size), making the comparison of clinical and anatomic results of limited value. Per- 
manent neurologic procedure-related complications occurred in $7.4 \%$ of the procedures in the stent placement group versus $3.8 \%$ in the nonstented group $(P=.644)$. Procedure-related death occurred in $4.6 \%$ in the stent placement group and $1.2 \%$ in nonstented group $(P=.006)$. Follow-up was available in only $52.7 \%$ of the patients, and angiographic recurrence was observed in $14.9 \%$ in the stent placement group versus $33.5 \%$ in the nonstented group.

Jahshan et $\mathrm{al}^{16}$ reported different results in a single-center series dealing with 489 aneurysms in 459 patients with similar permanent event-related morbidity in nonstented and stent placement groups, with higher rates of complete occlusion in stented aneurysms.

On the contrary, in a retrospective, single-center series by Hwang et $\mathrm{al},{ }^{17}$ in a relatively small group of 86 aneurysms treated with coils alone and 40 aneurysms treated with stent and coils, the rates of progressive occlusion at 2-year follow-up (42.5\% in the stent placement group and $39.5 \%$ in the nonstented group) and recanalization $(17.5 \%$ in the stent placement group and $21.0 \%$ in the non-stented group) did not statistically demonstrate any significant difference.

In the current article, in their single-center, retrospective series, Chalouhi et al $^{1}$ compare 69 patients treated with SAC and 32 patients treated with BAC. The 2 groups were comparable except for aneurysm status; in the BAC group, $65.6 \%$ of the aneurysms were ruptured, and in the SAC group, $11.5 \%$ of the aneurysms were ruptured $(P<.001)$. The rates of complete aneurysm occlusion were significantly higher in the SAC group $(75.4 \%)$ versus the BAC group $(50 \% ; P=.001)$. In the incompletely coiled group, progressive aneurysm occlusion occurred more frequently in the SAC group $(76.6 \%)$ than in the BAC group $(42.8 \%, P=.02)$. The retreatment rates were significantly lower with SAC (4.3\%) than with BAC (15.6\%, $P=.05)$. The aneurysm rupture status plays an important role in recanalization, and as the BAC and SAC groups are different regarding this status, it is difficult to know the true significance of these results.

SAC has been used for more than 10 years, and the data are lacking to know precisely whether the safety and efficacy are different between SAC and standard coiling. The only way to answer these important questions is to build a randomized, controlled trial comparing stent placement versus nonstenting in a large group of patients to determine whether the addition of a stent to standard coiling can decrease the recurrence rate without increasing morbidity and mortality. ${ }^{18}$

The development of new techniques such as flow diversion and flow disruption will also modify the global strategy of aneurysm treatment, and the respective places of stenting, flow diversion, and flow disruption must be defined according to their safety and efficacy profile. ${ }^{19,20}$ Currently, flow diverters are indicated and recommended in sidewall, unruptured aneurysms, singularly those located on the ICA, but these aneurysms are also a good indication for stent placement. Flow disrupters are used in wide-neck bifurcation aneurysms (ruptured and unruptured). Aneurysm locations treated with flow disruption are the MCA, basilar tip, ICA bifurcation, and the anterior communicating artery. For these locations, stent placement can also be used (singularly for unruptured aneurysms), including more complex techniques such as $\mathrm{Y}$ and $\mathrm{X}$ stent placement. A direct comparison of stent placement and coiling versus flow diversion or flow disruption will be mandatory in the future to directly compare the safety and efficacy of these techniques and to specify their respective place in aneurysm management.

Disclosures: Laurent Pierot-RELATED: Consultancy: Codman, Covidien/ev3, MicroVention, Penumbra, and Sequent. Christophe Cognard — RELATED: Consultancy: Codman, Covidien/ev3, MicroVention, Sequent, and Stryker.

\section{REFERENCES}

1. Chalouhi N, Starke RM, Koltz MT, et al. Stent-assisted coiling versus balloon remodeling of wide-neck aneurysms: comparison of angiographic outcomes. AJNR Am J Neuroradiol 2013;34:1984-89

2. Molyneux A, Kerr R, Stratton I, et al. International Subarachnoid Aneurysm Trial (ISAT) of neurosurgical clipping versus endovascular coiling in 2143 patients with ruptured intracranial aneurysms: a randomised trial. Lancet 2002;360:1262-63

3. Pierot L, Spelle L, Vitry F, ATENA Investigators. Immediate clinical outcome of patients harbouring unruptured intracranial aneurysms treated by endovascular approach: results of the ATENA Trial. Stroke 2008;39:2497-504

4. Cognard C, Pierot L, Anxionnat R, et al, CLARITY Investigators. Results of embolization used as the first treatment choice in a consecutive non selected population of ruptured aneurysms: clinical results of the Clarity GDC study. Neurosurgery 2011;69:837-41

5. Ferns SP, Sprengers MES, von Rooij WJ, et al. Coiling of intracranial aneurysms: a systematic review on initial occlusion and reopening and retreatment rates. Stroke 2009;40:e523-29

6. Moret J, Cognard C, Weill A, et al. The "remodelling technique" in the treatment of wide neck intracranial aneurysms. Intervent $\mathrm{Neu}$ roradiol 1997;3:21-35

7. Pierot L, Cognard C, Spelle L, et al. Safety and efficacy of balloon remodelling technique during endovascular treatment of intracranial aneurysms: critical review of the literature. AJNR Am J Neuroradiol 2012;33:12-15

8. Pierot L, Spelle L, Leclerc C, et al. Endovascular treatment of unruptured intracranial aneurysms: comparison of safety of remodeling technique and standard treatment with coils. Radiology 2009;251:846-55

9. Pierot L, Cognard C, Anxionnat R, et al, for the CLARITY Group. The remodelling technique for endovascular treatment of ruptured intracranial aneurysms is more efficacious than standard coiling with a similar safety. Radiology 2011;258:546-53

10. Shapiro M, Becske T, Sahlein D, et al. Stent-supported aneurysm coiling: a literature survey of treatment and follow-up. AJNR Am J Neuroradiol 2012;33:159-63

11. Lee SJ, Cho YD, Kang HS, et al. Coil embolization using the selfexpandable closed cell stent for intracranial saccular aneurysm: a single center experience of $\mathbf{2 8 9}$ consecutive aneurysms. Clin Radiol 2013;68:256-63

12. Gao X, Liang G, Li Z, et al. Complications and adverse events associated with Neuroform stent-assisted coiling of wide-neck intracranial aneurysms. Neurol Res 2011;33:841-52

13. Fargen KM, Hoh BL, Welch BG, et al. Long-term results of Enterprise stent-assisted coiling of cerebral aneurysms. Neurosurgery 2012;71:239-42

14. Gentric JC, Biondi A, Piotin M, et al. Safety and efficacy of Neuroform for treatment of intracranial aneurysms: a prospective, consecutive, French multicentric study. AJNR Am J Neuroradiol 2013;34:1203-08 
15. Piotin M, Blanc R, Spelle L, et al. Stent-assisted coiling of intracranial aneurysm: clinical and angiographic results in 216 consecutive aneurysms. Stroke 2010;41:110-15

16. Jahshan S, Abla AA, Natarajan SK, et al. Results of stent-assisted vs nonstent-assisted endovascular therapies in 489 cerebral aneurysms: single-center experience. Neurosurgery 2013;72:232-39

17. Hwang G, Park H, Bang JS, et al. Comparison of 2-year angiographic outcomes of stent- and nonstent-assisted coil embolization in unruptured aneurysms with unfavorable configuration for coiling. AJNR Am J Neuroradiol 2011;32:1707-10

18. Darsault TE, Raymond J, for the STAT Collaborative Group. The design of the Stenting in Aneurysm Treatments (STAT) trial. J Neurointervent Surg 2012;4:178-81

19. Pierot L. Flow diverter stents in the treatment of intracranial aneurysms: where are we? J Neuroradiol 2011;38:40-46
20. Pierot L, Liebig T, Sychra V, et al. Intrasaccular flow-disruption treatment of intracranial aneurysms: preliminary results of a multicenter clinical study. AJNR Am J Neuroradiol 2012;33: 1232-38

L. Pierot

Department of Neuroradiology, Hôpital Maison-Blanche, CHU Reims,

Reims University, Reims, France

$$
\text { C. Cognard }
$$

Department of Neuroradiology, CHU Toulouse, Toulouse University, Toulouse, France 